\title{
Announcement of changes to the editorial board
}

Published online: 14 October 2020

(C) Springer Nature B.V. 2020

Tim Arnett has stepped down as an Associate Editor of the journal after many years of outstanding service. His contribution has been much appreciated and we thank him. Isabel Orriss, who is an excellent research scientist in the purinergic field, has agreed to become an Associate Editor.

Publisher's note Springer Nature remains neutral with regard to jurisdictional claims in published maps and institutional affiliations. 